\title{
BIMOMENT AND ITS INFLUENCE IN THE DRAFT prEN 1993-1-1: 2017
}

\author{
Y. Koleková*, I. Baláźz** L. Moroczová ${ }^{* * * *}$
}

\begin{abstract}
Critical analysis of the plastic resistance of I- and H-sections under interaction of bending moment a bimoment in the prEN 1993-1-1, 2017. Improvement proposals for the new draft prEN 1993-1-1.
\end{abstract}

Keywords: plastic resistance, bimoment, bending moment, interaction, I- and H- sections, Eurocodes.

\section{Introduction}

The resistances of the I- or H-sections to interactions of bending and torsion internal forces are missing in the current Eurocodes (EN 1993-1-1, 2005; EN 1999-1-1, 2007). New approaches are proposed for the new generation of Eurocodes (prEN 1993-1-1, 2017; prEN 1999-1-1, 2017), which will be available in 2021. They take take into account the interactions of the bending moment $M_{y, E d}$, the shear force $V_{z, E d}$, the bimoment $B_{E d}$, the warping torsional moment $T_{\omega, E d}$ and the St. Venant torsional moment $T_{t, E d}$ acting on Ior H-section. The numerical example shows the application of the procedure proposed for (prEN 1993-11, 2017). This procedure differs from the one proposed for (prEN 1999-1-1, 2017).

\section{Numerical example and application of ( prEN 1993-1-1, 2017) rules}

Simple supported beam loaded eccentrically by two transverse forces is investigated. The given data are as follows. Beam span $L=6 \mathrm{~m}$; rolled section IPE 300; two vertical transverse forces $F_{E d}=49.9 \mathrm{kN}$ located $1.5 \mathrm{~m}$ from supports; eccentricity of the transverse forces $e=0.07 \mathrm{~m}$; steel grade $\mathrm{S} 235$; partial safety factor for material $\gamma_{M 0}=1.0$; partial safety factor for action $\gamma_{\mathrm{F}}=1.5$.

The internal forces of bending and torsion were calculated using the analytical solutions both of the torsion differential equations: (i) without and (ii) with influence of shear which are given in (Baláž, 2004). It was confirmed the well known fact, that influence of shear for open cross-section is negligible. These analytical results were checked and compared with the numerical results obtained by the computer program IQ 100 (Rubin et al, TU Vienna). Both the analytical and the numerical results gave the identical results. The distributions of the torsion internal forces are shown in Figures 1, 2, 3 and 4.

The warping constant $I_{\omega}$, the torsion constant $I_{t}$, the shear torsion constant $I_{t, s}$, the torsion constant shear factor $v_{\omega}$ and the measure of warping $\mu_{\omega}$ may be calculated from the formulae derived by the authors for I- and H-sections. For the IPE 300 section their numerical values are as follows:

$$
\begin{gathered}
I_{\omega}=t_{f}\left(h_{w}+t_{f}\right)^{2} b^{3} / 24=125934 \mathrm{~cm}^{6} \\
I_{t}=\left(2 b t_{f}^{3}+h_{w} t_{w}^{3}\right) / 3-0.105 t_{f}^{4} 4=15.151 \mathrm{~cm}^{4}
\end{gathered}
$$

Assoc. Prof. Ing. Yvona Koleková, PhD.: Department of Structural Mechanics, Faculty of Civil Engineering, Slovak University of Technology in Bratislava, Slovak Republic, Radlinského 11; 810 05, Bratislava; SK, yvona.kolekova@stuba.sk

** Prof. Ing. Ivan Baláž, PhD.: Department of Metal and Timber Structures, Faculty of Civil Engineering, Slovak University of Technology in Bratislava, Slovak Republic, Radlinského 11; 810 05, Bratislava; SK, ivan.balaz@stuba.sk

**** Ing. Lýdia Moroczová, external PhD student at Department of Metal and Timber Structures, Faculty of Civil Engineering, Slovak University of Technology in Bratislava, Slovak Republic, Radlinského 11; 810 05, Bratislava, lidka.mo@gmail.com 


$$
\begin{gathered}
I_{t, s}=5\left(h_{w}+t_{f}\right)^{2} b t_{f} / 12=5597 \mathrm{~cm}^{4} \\
v_{\omega}=I_{t, s} / I_{t}=369.4, \quad \mu_{\omega}=v_{\omega} /\left(1+v_{\omega}\right)=0.997
\end{gathered}
$$

The beam mixed torsion parameters without the shear influence $(k L)$ and with the shear influence $\left(k L_{v}\right)$ are calculated from the formulae

$$
k L=\sqrt{\frac{G I_{t}}{E I_{\omega}}}=4.134, \quad k L_{v}=\sqrt{\mu_{\omega} \frac{G I_{t}}{E I_{\omega}}}=4.128
$$

Figures 1-4 illustrate the well known fact that for the open section the influence of the shear is negligible. The quantities calculated without the shear influence are in figures characterized by the dotted lines and the values in the brackets.

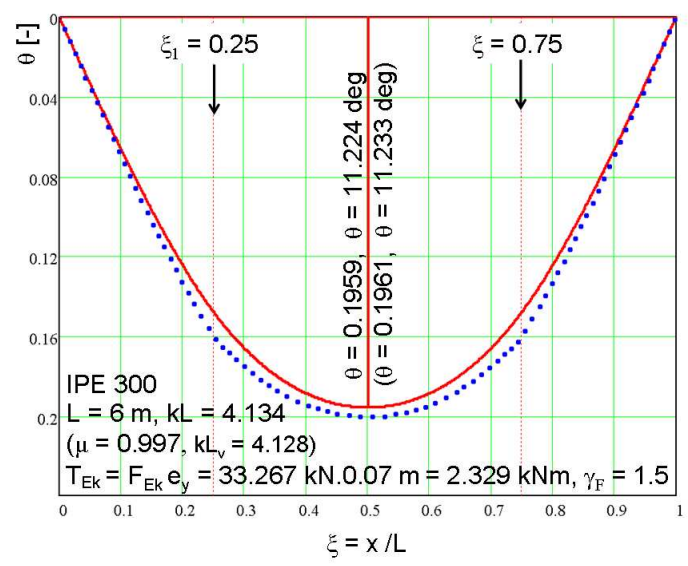

Fig. 1: Twist rotation $\theta(\xi)$ about axis $x$.

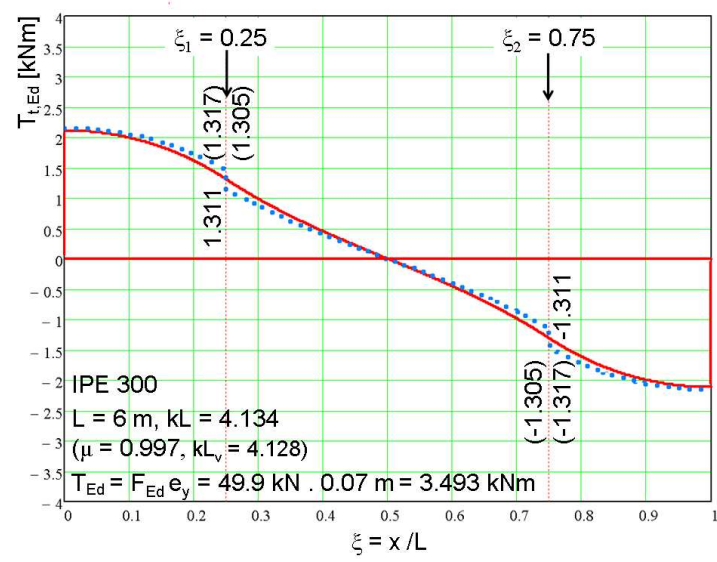

Fig. 2: St.Venant torsional moment $T_{t, E d}(\xi)$

To show the invisible small difference between the solid lines (the case without the influence of the shear) and the dotted lines (the case with the influence of the shear) the graphical distributions were drawn for $k L_{v}=0.9$ instead of the correct value $k L_{v}=0.997$. Otherwise no difference between the solid and the dotted lines would be seen in figures. The related numerical values in Figures 1-4 are calculated using the correct value $k L_{v}=0.997$.

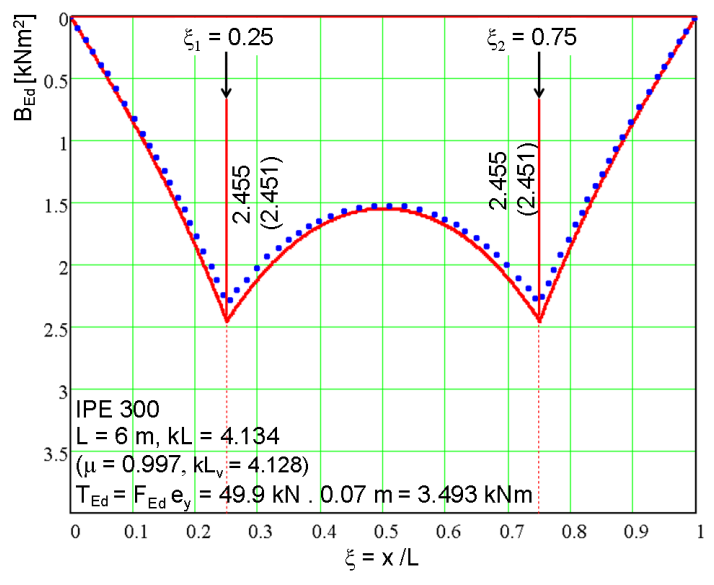

Figure 3. Bimoment $B_{E d}(\xi)$

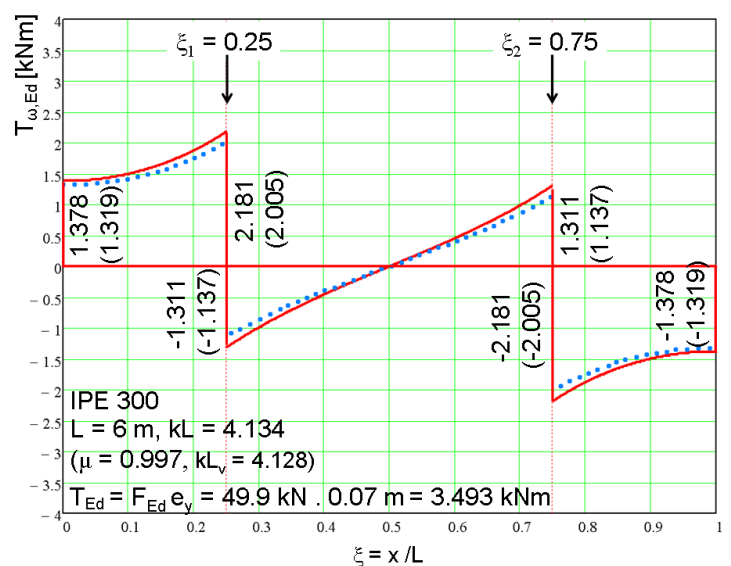

Figure 4. Warping torsional moment $T_{\omega, E d}(\xi)$

The verification performed according to (prEN 1993-1-1, 2017) for IPE 300 section. It is Class 1 section, therefore the plastic resistance of the cross-section is calculated.

$$
\begin{gathered}
A_{V z, E N}=A-2 b t_{f}+\left(t_{w}+2 r\right) t_{f}=5380-2 \times 150 \times 10.7+(7.1+2 \times 15) 10.7=2471.6 \mathrm{~mm}^{2} \\
\eta h_{w} t_{w}=1.2 \times 278.6 \times 7.1=2374 \mathrm{~mm}^{2} \\
A_{v z}=\max \left(A_{V z, E N} ; \eta h_{w} t_{w}\right)=2471.6 \mathrm{~mm}^{2}
\end{gathered}
$$




$$
\begin{gathered}
V_{p l, z, R d}=A_{v z} f_{y} /\left(\sqrt{3} \gamma_{M 0}\right)=2471.6 \times 235 /(\sqrt{3} \times 1.0)=335.34 \mathrm{kN} \\
\tau_{t, E d, w}= \pm \frac{T_{t, E d}}{I_{t}} t_{w}= \pm \frac{1.311 \mathrm{kNm}}{15.151 \mathrm{~cm}^{4}} 7.1 \mathrm{~mm}= \pm 61.44 \mathrm{MPa} \\
V_{p l, z, T t, R d}=\sqrt{1-\frac{\tau_{t, E d, w}}{1.25 f_{y} /\left(\sqrt{3} \gamma_{M 0}\right)}} V_{p l, z, R d}=\sqrt{1-\frac{61.44}{1.25 \times 235 /(\sqrt{3} 1.0)}} 335.34=267.8 \mathrm{kN} \\
M_{p l, y, R d}=W_{p l, y} f_{y} / \gamma_{M 0}=602.1 \mathrm{~cm}^{3} 235 \mathrm{MPa} / 1.0=141.5 \mathrm{kN} \\
\omega_{\max }=\frac{h_{w}+t_{f}}{2} \frac{b}{2}=\frac{278.6+10.7}{2} \frac{150}{2}=108.49 \mathrm{~cm}^{2} \\
\sigma_{w, E d, \text { max }}=\frac{B_{E d}}{I_{\omega}} \omega_{\max }=\frac{2.455 \mathrm{kNm}^{2}}{125934 \mathrm{~cm}^{6}} 108.49 \mathrm{~cm}^{2}=211.5 \mathrm{MPa} \\
M_{c, B, R d}=\sqrt{1-\frac{\sigma_{w, E d, m x}}{1.25 f_{y} / \gamma_{M 0}}} M_{p l, y, R d}=\sqrt{1-\frac{211.5}{1.25 x 235 / 1.0}} 141.5=74.88 \mathrm{kN} \\
\frac{M_{y, E d}}{M_{c, B, R d}}=\frac{49.9 \mathrm{kN} 1.5 \mathrm{~m}^{2}}{74.88 \mathrm{kN}^{2}}=1.0 \leq 1.0
\end{gathered}
$$

It means that $F_{E d}=49.9 \mathrm{kN}$ is the plastic action resistance $F_{p l . R d}$ of the beam under investigation. This procedure which is used in (prEN 1993-1-1, 2017) needs the following corrections:

(i) The Eurocodes prefer to use the internal forces instead of the stresses. The formula (16) should be replaced by the following formula, which contains the internal forces (not the stress) and gives the same numerical results as (16)

$$
M_{c, B, R d}=\sqrt{1-1.2 \frac{B_{E d}}{B_{p l, R d}}} M_{p l, y, R d}=\sqrt{1-1.2 \frac{2.455}{4.092}} 141.5=74.88 \mathrm{kNm}
$$

where

$$
W_{p l, \omega}=t_{f}\left(h_{w}+t_{f}\right) b^{2} / 4=1741 \mathrm{~cm}^{4}, \quad B_{p l, R d}=W_{p l, \omega} f_{y} / \gamma_{M 0}=4.092 \mathrm{kNm}^{2}
$$

(ii) It was shown in details in (Baláž et al., 2016a and 2016b), that formula (16) is incorrect. The correct formula proposed by the first author is

$$
M_{c, B, R d}=\sqrt{1-\frac{B_{E d}}{B_{p l, R d}}} M_{p l, y, R d}=\sqrt{1-\frac{2.455}{4.092}} 141.5=89.5 \mathrm{kNm}
$$

If the correct formula (20) would be used instead of incorrect (prEN 1993-1-1, 2017) formula (20) the plastic action resistance of the beam under investigation will be $F_{p l, R d}=54.94 \mathrm{kN}$. For this value the condition (17) becomes not fulfilled with $1.279>$ 1.0. It was shown in (Baláž, Koleková, 2017), were also the channel sections and the influence of the metal strengthening were investigated, that comparing with $F_{p l, R d}=54.94 \mathrm{kN}$ there is still some reserve in the plastic resistance. It is interesting to mention that (prEN 1993-1-1, 2017) contains the incorrect solution of the problem of the bending moment and the bimoment interaction, which was correctly, more deeply and in the very complex way (taking into account any internal forces of the bending and the torsion) solved in Russia and Ukraine already in the forties and fifties. See e.g. (Strel'bickaja, 1958) in (Baláž, Koleková, 2017). The symbol $M_{c, B, R d}$ should be replaced in (16), (18) and (20) by the symbol $M_{p l, B, R d}$. The evidence for above statements is as follows. For the zero bending moment one should obtain $B_{E d, \max }=B_{p l, R d}$. But from equation (16) or (18) one obtains $B_{E d, \max }=5 B_{p l, R d} d 6=0.8333 B_{p l, R d}$. The reason for this mistake is in the derivation of the final formula (16) from the formula (21) in which $\alpha=5$ instead of 6 was taken mistakenly: 


$$
M_{c, B, R d}=\sqrt{1-\frac{\sigma_{w, E d, m x}}{\frac{6}{\alpha} \frac{f_{y}}{\gamma_{M 0}}}} M_{p l, y, R d}=\sqrt{1-\frac{\sigma_{w, E d, m x}}{1.25 \frac{f_{y}}{\gamma_{M 0}}}} M_{p l, y, R d}
$$

The following formula given in (EN 1993-1-1, 2005; prEN 1993-1-1, 2017)

$$
V_{p l, z, T, R d}=\sqrt{1-\frac{\tau_{t, E d}}{1.25\left(f_{y} / \sqrt{3}\right) / \gamma_{M 0}}} V_{p l, z, R d}
$$

contains incidentally the factor 1.25 too. The formula (22) has nothing to do with (21) and its correctness is very questionable as it was shown in (Baláž et al., 2016c).

The above criteria may be used only if the bending moment cross-section plastic resistance is not reduced due to shear stress $\tau_{V z, E d}$ in the web and the bimoment cross-section plastic resistance is not reduced due to shear stresses $\tau_{t, E d}$ or $\tau_{\omega, E d}$ in the flanges. In the numerical example $V_{z, E d} / V_{p l, z T, R d}=0.186<0.5$ and the bending moment resistance is not necessary to reduce according to EN 1993-1-1. For the case $V_{z, E d} /$ $V_{p l, z, T t, R d}>0.5$ one may find in (EN 1993-1-1, 2005; prEN 1993-1-1, 2017) the procedure how to reduce the bending moment due to the shear force. In the section next to the force $F_{E d}=49.9 \mathrm{kN}$. The shear stress in the flanges due to the shear force $\tau_{V, E d}=6.48 \mathrm{MPa}$ and the warping torsional stress $\tau_{\omega, E d}=7.05 \mathrm{MPa}$ is usually negligible. But the St. Venant torsional shear stress in the flanges $\tau_{t, E d}= \pm 90.53 \mathrm{MPa}$ is not negligible. The total shear stress in the flanges is $\tau_{V, E d}+\tau_{\omega, E d}+\tau_{t, E d}=104.05 \mathrm{MPa}$.

\section{Conclusions}

The proposal (see formula (20)) how to improve incorrect formula (16) used in prEN 1993-1-1, 2017. The all above analytical results and formulae of the authors were verified and confirmed by the computer programs DUENQ (Dlubal Software) and QST-TSV-3Blech (RU Bochum).

\section{Acknowledgement}

Project No. 1/0603/17 was supported by the Slovak Grant Agency VEGA.

\section{References.}

Baláž, I. J. (2004) Thin-walled steel structures. Influence of torsion in large thin-walled bridge structures (in Slovak). ES STU Bratislava, $1^{\text {st }}$ edition, 1984: 1- 168. $5^{\text {th }}$ expanded edition. 2004: 1-295.

Baláž, I., Kováč, M., Živner, T. Koleková, Y. (2016a) Resistances of I-Section to Internal Forces Interactions. In Key Engineering Materials: Aluminium Constructions: Sustainability, Durability and Structural Advantages. Selected, Trans Tech Publications inc.: peer reviewed papers from the 13th International Aluminium Conference INALCO 2016, September 21-23, 2016, Naples, Italy. Vol. 710, s. 309-314. ISSN 1013-9826.

Baláž, I.,J., Kováč, M., Živner, T.J., Koleková, Y, P. (2016b) Plastic resistance of H-section to interaction of bending internal forces $\mathrm{M}_{\mathrm{y}, \mathrm{Ed}}, \mathrm{V}_{\mathrm{z}, \mathrm{Ed}}$ and torsion internal forces $\mathrm{B}_{\mathrm{Ed}}, \mathrm{T}_{\omega, \mathrm{Ed}}$ and $\mathrm{T}_{\mathrm{t}, \mathrm{Ed}}$. International Journal "Interdisciplinarity in Theory and Practice". Journal for presentation of interdisciplinary approaches in various fields. ITPB Nr. 10, year: 2016. ISSN 2344-2409, p.311-315.

Baláž, I., Kováč, M., Živner, T., Koleková, Y. (2016c) Plastic resistance of I-section to interaction of bending and torsion in current and future metal Eurocodes. Proceedings of 2nd International Conference on Engineering Sciences and Technologies. Tatranské Matliare. High Tatras Mountains, Slovak Republic. $29^{\text {th }} \mathrm{June}-1^{\text {st }} \mathrm{July}$ 2016. Paper No. 010, p.1-4. ISBN 978-80-553-2564-4.

Baláž, I., Koleková, Y. (2017) Resistances of I- and U-sections Combined bending and torsion internal forces. EUROSTEEL 2017, September 13-15, 2017, Copenhagen, Denmark. Paper No. 13_12_ 772 on USB, pp. 1-10.

EN 1993-1-1 (2005) and Corrigendum AC (2006). Eurocode 3 - Design of steel structures, Part 1-1: General rules and rules for buildings. CEN Brussels.

EN 1999-1-1 (2007) and Amendment A1 (2009) and Amendment A2 (2013). Eurocode 9 - Design of aluminium structures. Part 1-1: General structural rules.

prEN 1993-1-1 (2017) Eurocode 3 - Design of steel structures, Part 1-1: General rules and rules for buildings. CEN/TC 250/SC 3/WG 1, N 229. Final Draft prepared by the Project Team SC3.T1. Date of document: 201712-18. Document stage: CEN Enquiry. CEN Brussels.

prEN 1999-1-1 (2017) Eurocode 9 - Design of aluminium structures. Part 1-1: General structural rules. CEN/TC 250/SC 9, N 579. prEN 1999-1-1 Final Draft marked. Date of document: 2017-11-02. CEN Brussels. 